\title{
Student perspective and lessons learned from participating in ESA ESEO mission
}

\author{
Dániel Skriba, Márton Borsi, Antal Bánfalvi, \\ László Csurgai-Horváth, József Szabó, Zsolt Váradi \\ Budapest University of Technology and Economics \\ Department of Broadband Infocommunications and Electromagnetic Theory \\ Budapest, Hungary
}

\begin{abstract}
In this paper we would like to present what we have learnt by participating in the ESA's European Student Earth Orbiter (ESEO) mission which is an educational satellite program. We gained hands-on experience by manufacturing, adjusting and testing the components of the Power Distribution Unit (PDU) subsystem and the Langmuir Probe experiment (LMP). ESA provided the opportunity to participate in courses organized by ESA Academy. At the last phase of the preparation we visited Sitael S.p.A. in Forli for the final testing of our modules before assembly, where we could work together with Sitael's experts in a space industry grade environment. The Assembly Integration and Testing (AIT) workshop in ESTEC provided great educational value for all of the LMP and PDU team members.
\end{abstract}

Keywords-ESEO, ESA, Academy, student satellite, BME team, hand-on experience, career

\section{ESEO MISSION}

The European Student Earth Orbiter is an educational micro satellite project for university students. Ten Universities from eight ESA Member States have participated in ESEO with more than 600 university students involved in the project. The educational objective of the project is to give hands-on experience of a real space mission for university students in order to prepare a well-qualified technical workforce for the European space sector. The students were responsible for developing and testing the payload (scientific instruments or technology demonstration experiments), key satellite subsystems and the ground segment to the mission. Besides the educational purposes, ESEO has objectives during its 6 months long operational mission phase such as taking pictures of the Earth's surface, measuring radiation levels and plasma properties on Low Earth Orbit (LEO). Furthermore, testing freshly developed technologies for future ESA small-satellite missions was another purpose of ESEO. By carrying a radio payload, it also enables radio amateurs to establish connections with the spacecraft on VHF band moreover the UHF and Sband ground segment (ground stations and Mission Control Centre) is fully operated by student teams [1].

The ESEO satellite was launched from the Vandenberg Air Force Base in California (US) on 3 December 2018, by a SpaceX Falcon 9 launcher, together with several other micro, nano and pico satellites from all over the world. It was set into LEO within the frame of the Spaceflight's SSO-A: SmallSat Express dedicated rideshare mission [1].

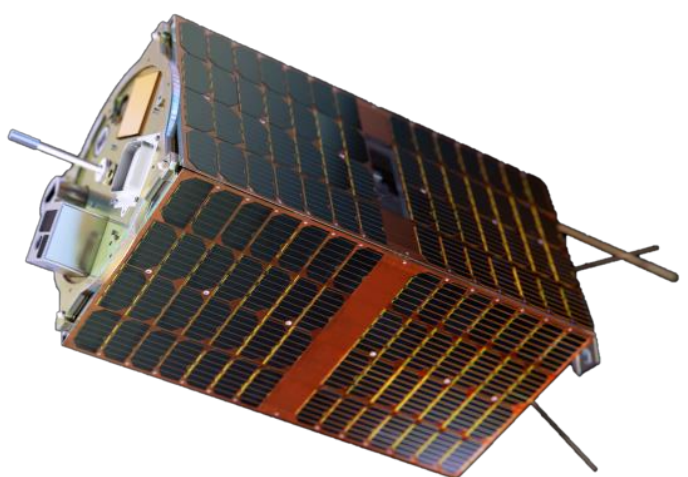

Fig. 1. ESEO model [1]

\section{ABOUT OUR TEAM}

In the past thirteen years many students from Laboratory of Space Technology worked on the ESEO project along with professionals. Our laboratory has a heritage of working on many spacecrafts such as the Philae the lander unit of the Rosetta space probe. The laboratory has a method of involving students, supervised by professionals, in the ongoing projects. The students can gain hands-on experience by taking part in designing, building and testing a spacecraft component.

In the past years many students from the laboratory worked on the ESEO project. Some of them continued their careers in the space industry or stayed at the laboratory as PhD students. The current student team members have joined the ESEO mission three years ago. During this time, we worked on two different parts of the satellite. We also participated in the events organised by ESA Academy to widen our knowledge about the ESEO satellite and other space related projects.

In our laboratory, besides of circuit simulations and modelling, students usually build them on test panels. This is an effective way for students to practice soldering and most importantly, they get a very deep understanding of the device which they build. These models are also good to test most of the functionality and parameters of the circuit. 


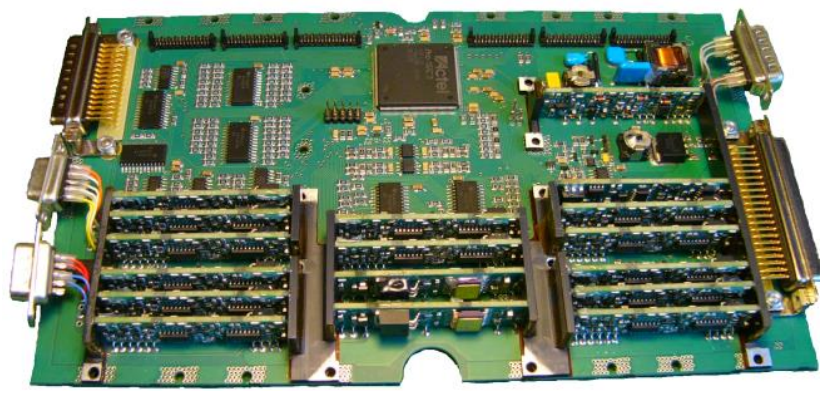

Fig. 2. ESEO PDU-EBB2

\section{EXPERIENCES FROM PDU}

The main objective of the Power Distribution Unit (PDU) is to supply electrical power to the subsystems of the satellite and payloads and to prevent the overload of the main power bus. The unit consists of two identical and connected PCBs called motherboard, in order to provide the required redundancy as one of them is the Main board and the other is the Redundant. In order to manage the power distribution and prevention functions each payload and subsystem has a dedicated Latched Current Limiter (LCL) circuit as daughterboards on the PDU which connects them to the main power bus. Every LCLs has an individual current limit and undervoltage protection level set as referred by the requirements of the payload or the subsystem. The detailed function of the PDU and the LCLs were presented last year at the 2nd Symposium on Space Educational Activities [2].

As students of the laboratory we got involved in the work on the PDU. We could take part in various tasks. One big job was to calibrate each LCL individually to meet the required current and undervoltage classes. Students were responsible for soldering the calibration components into the circuit where they learned the technique of handling and soldering according to the requirements for space grade components. After calibration students carried out the functional, thermal and EMC tests of the PDU and the LCL-s alongside with professionals. During the EMC tests we studied many ESA ECSS standards witch a spacecraft must match [3]. It was the task of the students to prepare the test environment including test boards and other preparations for the measurements.

During this work we got deeper understanding of how this type of current limiter works. We can carry on this experience in our further careers. To mention an example, one of the students wrote his BSc thesis on the potential of further improving this circuit.

\section{KNOWLEDGE GAINED FROM LMP EXPERIMENT}

The instrument of Langmuir Probe is a scientific experiment which aims to measure the plasma properties in the ionosphere, the upper regions of the atmosphere of Earth. The device can examine the electron temperature, electron density and ion density by obtaining the voltage-current characteristic of the plasma which depends on the parameters mentioned above. From further analysis of this curve, additional scientific results can be achieved such as conclusions on solar activity and plasma anomalies for instance the South Atlantic Anomaly.
The instrument consists of two well separable parts such as the Langmuir Control Box and the Langmuir Detector. Inside the surface treated metallic housing, the device contains three well separated circuitries such as the Amplifier (AMP), the On Board Data Handler (OBDH) and the Power Supply (PS). The Amplifier is responsible for the low signal level measurement of plasma voltage and current, so the precise adjustment of the measuring circuits was necessary during the development. Therefore, we could have an insight to the principles of the low signal level measurements and the complex selection process of proper electrical components. For instance, the temperature independence was an important point so we carried out lots of design and examination in climate chamber to make components more resistive against temperature change. The OBDH is the central data processing unit of the experiment so we could learn a lot about the design of digital circuits such as the PCB design and the operation of the microcontroller which is the heart of the OBDH. The PS unit is the own DC-DC converter of the device. It is a complex flyback converter with eight different outputs therefore during the developing phase we could obtain a lot of knowledge about the design principles of switching-mode power supplies. Moreover, the design and manufacture of unique components such as the flyback transformer have also been done by students.

When the LMP was prepared, several qualification tests were carried out both on the engineering model (LMP-EBB) and on the flight model (LMP-PFM). They were subjected to random and sinusoidal vibration tests, cyclic thermal test with functional examinations on marked temperatures $\left(-25^{\circ} \mathrm{C}\right.$, $+25^{\circ} \mathrm{C},+70^{\circ} \mathrm{C}$ ) furthermore conducted and radiated EMC measurements. From this complex test campaign, we could become familiar with the principals and practice of special test methods that are required to qualify instruments for small satellite board.

To evaluate the scientific data provided by LMP, our student team prepared a special software to process and evaluate the information forwarded by the ground station for scientific data in Munich. Therefore, the analysis of the dataflow is possible and required plasma properties would be concluded [4].

\section{TRAINING COURSES BY ESA ACADEMY}

During the whole lifetime of the program, ESA Academy organised several trainings and workshops for the ESEO student teams. Thus being members of the ESEO-PDU and ESEO-LMP teams, in May and July of 2018, ESA Academy provided us a wonderful and unique opportunity to attend two training courses about Spacecraft Operation and Spacecraft Communication which were held by the staff of Training and Learning Centre in Redu, Belgium. Both events were held by a distinguished tutor who is a member of the ESA operator team in ESOC so we could get lot of first-hand experience from a real professional. We were taught about the principles of operation of the functional parts of a spacecraft such as power, communication or thermal subsystems. We could obtain useful knowledge about establishing communication link with spacecrafts, managing the operation during mission phase with the most efficiency and selecting ground stations to keep in touch with our satellite. Those lectures were very interesting 


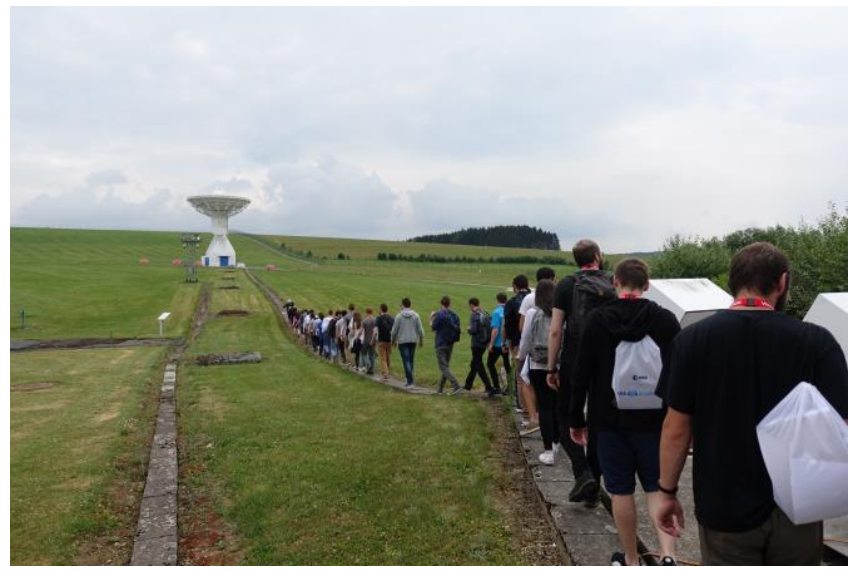

Fig. 3. Students at Redu station [1]

because the lecture material was always accompanied with examples and interesting stories from real life experiences.

As an additional program beside the lectures, we had the opportunity to visit the ESA ground station in Redu where we got a full guided tour around the site. We could see the enormous high gain parabolas during operation and we were invited into the operational room where we saw how to transform the learnt principles into practice and where we experienced how real satellite tracking works.

These two training courses were also such great social events because we had the possibility to meet university students from different countries of Europe, with similar fields of interest on space sciences and technologies. We could work together on our own imaginary space mission, so we shared a lot of knowledge and experience and we acted as a real spacecraft operator team which was as interesting as the lectures.

\section{HANDS-ON EXPERIENCE IN FORLI}

After all units of the satellite had been completed and as the final integration approached, every university team was invited by the prime contractor SITAEL to deliver their own instruments. Furthermore, we had to carry out a final test process in order to obtain the final qualification of being onboard and getting prepared for the platform integration. So in August of 2018, our team was headed to Forli carrying the models of LMP with ourselves. The PDU had been shipped to the prime contractor previously for being an essential part of the Power Subsystem of the satellite. It was required to deliver not only the flight unit but the engineering model, because the EBBs had been assembled into the avionic test bench, called Flatsat, which is a full counterpart of the flight model of ESEO and contains the engineering models of all onboard units.

In Forli, we had the opportunity to test our instruments in real space industrial environment and to get more practice in the use of industrial measurement equipment. This was also a great experience that we were working in a clear room with the help of professionals of SITAEL which collaboration was an outstanding chance to share knowledge with each other. Fortunately, based on the results of the final tests, both of our

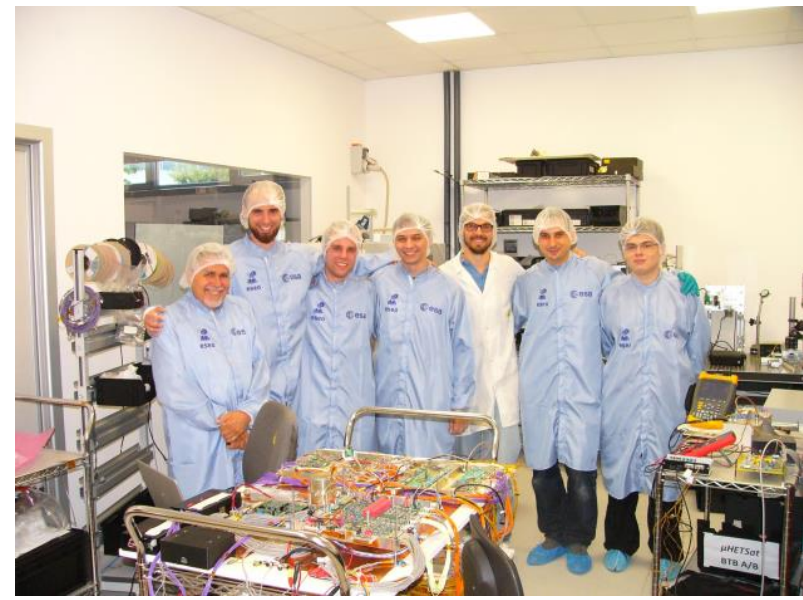

Fig. 4. BME team at SITAEL

instruments obtained the qualification to be assembled to the board of ESEO.

Although our days were busy with lots of work, we had the honorific invitation of being interviewed by an ESA representative about our parts in the ESEO mission. We could briefly describe our experience about the project, about our instruments and we could share the happiness and excitement about the approaching launch event.

\section{AIT WORKSHOP}

After the satellite was assembled, ESA Education Office organised the Assembly Integration and Testing (AIT) workshop in Noordwijk. The main purpose of the workshop was to gather all the teams from every participating university so the students and professionals could meet and exchange knowledge that they learned along the way. During the workshop we attended several presentations about the Test Campaign and of the ESEO. We learned about vibration, thermal vacuum and EMC testing carried out by industrial and ESA professionals on the whole satellite.

In one of the breaks, they showed us a special virtual reality program in which we could dissemble the ESEO. This technology could help engineers of the future to work together in a virtual laboratory on life-size 3D model even if they are in different countries.

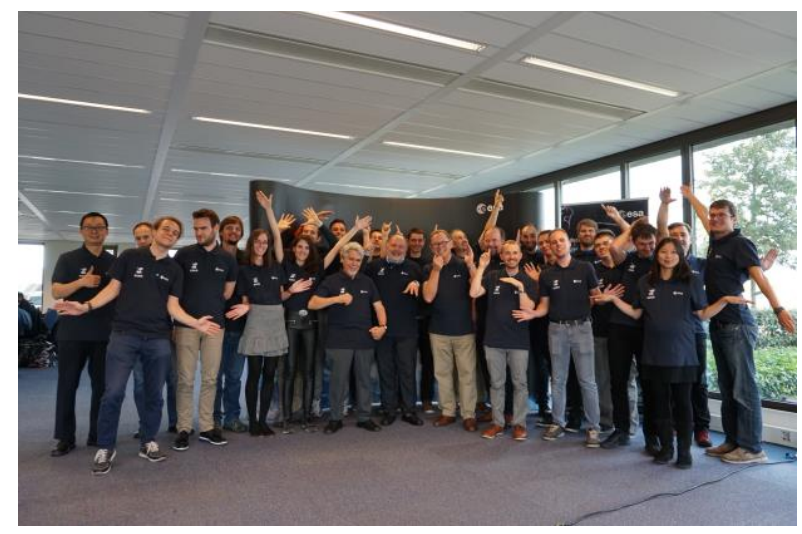

Fig. 5. Group picture of the AIT Workshop [1] 


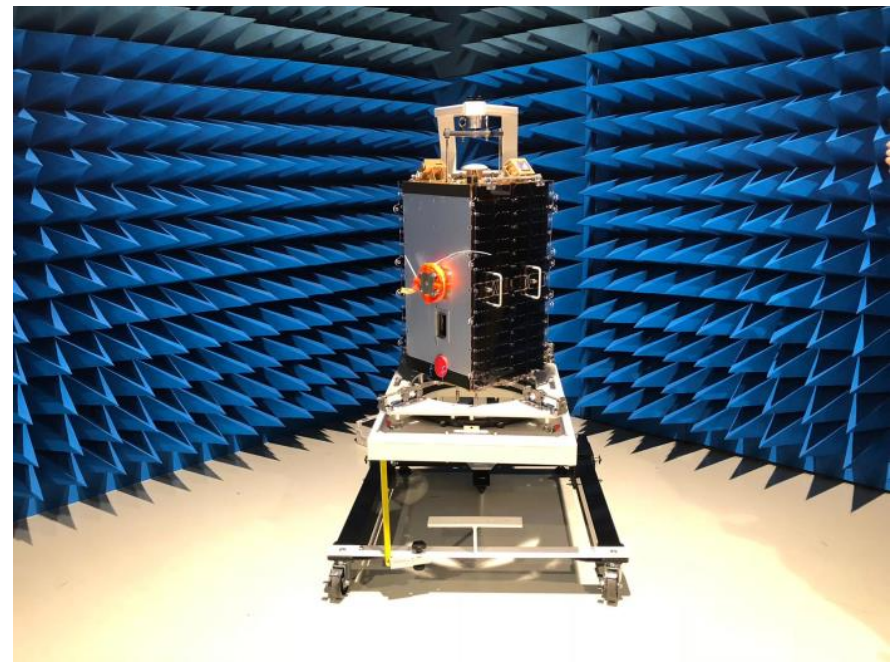

Fig. 6. Complete ESEO satellite [1]

We also visited the ESA's space research and technology centre, ESTEC. We had the opportunity to get a glimpse into different sites of the establishment where the ESEO was tested for example we could get a sight into the anechoic chamber. At each place, we got a brief description of a way how different tests were conducted on the student satellite. The best experience of our visit was when we saw the fully integrated ESEO, the result of the hard work of many universities

\section{SUMMARY}

The ESEO satellite was a great opportunity for everyone who worked on this project to gain invaluable hands-on experience in space technology. We benefited from working with university and ESA professionals and from participating in the courses and workshops organised by ESA Academy. We also got to know other university students and professionals on social events and team projects during these courses. From these opportunities, we enriched with many useful knowledge and experiences and established new relationships with fellow students. All these knowledges will be a huge help in our future careers. We are very grateful to ESA Academy for the ESEO project and for the educational programs which came with it.

\section{REFERENCES}

[1] European Space Agency, „ESEO,” 2019. [Online]. Available: https://www.esa.int/Education/ESEO.

[2] M. Borsi, D. Skriba, A. Bánfalvi, J. Szabó, Z. Váradi és L. Csurgai, „The ESEO Power Distribution Unit,” Budapest, 2018.

[3] M. Borsi, D. Skriba, F. Lénárt, A. Bánfalvi, J. Szabó és Z. Váradi, „Emc Testing Aapproach For Power Distribution Unot of Small Satellite," Budapest, 2019.

[4] V. Qiao, K. Tamás, Z. Váradi, J. Szabó és A. Bánfalvi, „In-situ Observation of Ionospheric Plasma Aboard ESEO,” Leicester, 2019. 